\title{
Publishing in transition - do we still need scientific journals?
}

\author{
Alexander Grossmann* \\ HTWK University for Applied Sciences Leipzig, Gustav-Freytag-Strasse 42, 04277 Leipzig, Germany \\ *Corresponding author's e-mail address: alexander.grossmann@htwk-leipzig.de
}

Published online: 4 September 2015 (version 1)

Cite as: Grossmann A., ScienceOpen Research 2015 (DOI: 10.14293/S2199-1006.1.SOR-SOCSCI.ACKEOY.v1)

Reviewing status: Please note that this article is under continuous review. For the current reviewing status and the latest referee's comments please click here or scan the QR code at the end of this article.

Primary discipline: Education

Secondary discipline: Information \& Library science, Physics

Keywords: Open Access, Scholarly Publishing, Academic Publishing, Alternative Article Metrics, Repositories, Journals, Social Networks, Peer Review

\begin{abstract}
For decades, scientific journals were the only way to communicate new research findings. Up until today, very little has changed in that respect. The overwhelming majority of all scientific journals still functions as they did in the times when there was no Internet, no social networks, or crowd-based knowledge platforms. Is this form of dissemination of research findings still suitable in the 21st century? The author says: no.
\end{abstract}

\section{AWAY WITH CANNED KNOWLEDGE?}

A year ago, neurogeneticist Björn Brembs spoke of the "digital stone age" as he described the prevailing state of the digital infrastructure in the sciences and thereby spoke of the failure of many institutions to document and communicate research findings in a more efficient and possibly more cost-effective manner than theretofore [1].

One of the several examples he named was the inability of specialized journals to adapt to the possibilities of the digital age in terms of the processing of data, and also the unimpeded access to scientific findings and the resultant academic discourse. Andreas Degkwitz, director of the university library of the Humboldt University drastically formulated it in his essay in the Tagesspiegel (June 16, 2014) as: "Weg mit den Wissenskonserven" ("Away with canned knowledge") [2]. So are articles in specialized journals really "dinosaurs," as Degwitz describes them? How could digital publishing fundamentally change the work of scientists in the 21st century?

For decades, if not centuries, the task of specialist journals in the sciences was clearly defined: They served to record and disseminate research findings in a citable form. The obvious purpose of the emergent scientific publishers was to organize this process and implement it on the production side. Initially, the dissemination of the content took place exclusively through libraries, which obtained the journals by subscription. What many scientists are not aware of today is this: Scientific journals first began to introduce the process of peer review as a means of quality assurance in the 1950s. Independent experts thereby examine the submitted manuscript before it is accepted for publication or rejected in its current form. In addition, many editors have a further procedure to filter works in "their" journals (editorial pre-selection), whereby they reject submitted manuscripts for various reasons prior to peer review. More than 20,000 journals worldwide - mostly English language - in the natural sciences, technical, and medical disciplines (STM) alone have worked in this way to date.

\section{THE DIGITAL WORLD IS TAKING HOLD IN SCIENTIFIC COMMUNICATION}

In the age of printed works, up to the mid-nineties, this process and the associated division of tasks were not only an established method, but also the best way to document and circulate research findings. That changed with the diverse possibilities, which newly arose (not just in daily life) at the turn of the century through the emergence of the Internet and digital media. All of a sudden, anytime and anywhere, it was possible to access digital copies of content, come into discussion with other Internet users, change or update data, share it with the click of a mouse, and so forth. Social networks became components of the uncomplicated exchange of information, a part of daily routine that many people cannot imagine life without. Blogs represented a new way to share one's own ideas without having to rely on journals or magazines. In some scientific fields, such as mathematics, physics, or information technology these possibilities have been in active use since 1991, as impressively shown by the repository arXiv, which posted its one-millionth article at the start of 2015. Meanwhile, this concept was expanded to the biological sciences through an independent initiative at Cold Spring Harbor Laboratory (bioRxiv). Even if these pre-print articles are not subject to peer review, many researchers use arXiv to be informed about the results of competing research groups immediately after the publication of their articles. The reviewed version, which may only appear in a specialty journal months later, plays only a subordinate role in 
information, particularly since arXiv introduced its own citation system in order to make it possible to reference articles posted there unambiguously.

Why do experienced researchers first post their articles on a repository instead of waiting for a publication in a renowned journal? Aside from saving time in publication, the claim to precedence plays a greater role, and not only in biomedical research. Moreover, in this manner, the articles are always directly available to scientific discourse, which in turn can lead to modifications or additions to the text in later versions, rather than appearing "written in stone" in a scientific journal. Despite these advantages, this procedure has not yet taken hold in many scientific fields, which may be due to a lack of a relevant technical platform or the skepticism of researchers. The critics' ever-repeated argument is that a system like arXiv only makes sense because physicists work in huge groups and already know each other's results and shared them with each other anyhow. This explanation misunderstands both the structure of physicists' research and the actual use of arXiv: The overwhelming majority of work posted there was produced by few authors or only one author, and only very few physicists work in high-energy physics. In 2006, the mathematician Grigori Perelman received the Fields Medal, which in mathematics has the status of the Nobel Prize, for his proof of the Poincaré Conjecture, which he published exclusively in arXiv [3]. Would it not then be logical to consider a system of documentation and dissemination of scientific results, one that makes use of the principle of a preprint server, such as, for example, arXiv? But one that, additionally, adds the established procedures of quality assurance - by means of the contemporary technical, digital possibilities, and not with the processes that base their workflow on analog processes like last century's print technology?

\section{A NEW PLATFORM - THE THOUGHT EXPERIMENT}

What would such a system need to look like? One that we could uncouple from the established procedures and business models of the publishing industry and could develop on fresh ground, described by the physicist as a "thought experiment"? First, we would need a virtual space that allows researchers to post their latest results as manuscripts. That would not necessarily need to be a single physical platform, as we know that nearly all institutions possess sufficient server capacities to meet this requirement. It would thus be enough to save merely the metadata on the new platform, with the usual bibliographical information and the abstract and a link to the peripherally stored document. If the author uses a repository such as arXiv, this already fulfills the task of a decentralized server. The format in which the contributions are available on the server or repository is irrelevant as they can be displayed readably in any form, regardless of platform, once converted into XML. Additionally, the author can opt to link his posted article to further data, and source material on his institution's server in order to support the verifiability of his results - an important requisite for the reproducibility of research findings these days. The article obtains a document object identifier (DOI) immediately after being posted to the platform, which ensures the unambiguous identification and thus citability of the article.

In this way, as a central contact point for the newest scientific findings, so to speak, the new platform "gathers" the peripherally available works from all research fields. To facilitate easier findability of relevant works, the user can navigate via full-text search or modify the search according to specified criteria. Semantic algorithms or user profiles, as we know them from other platforms in our daily lives, support the reader in his search for relevant works that might have been read by other researchers with the same interest emphasis anonymized, of course. In this way, one can quickly find articles that most support one's own research among the hundred or more new works that are posted each week. What is also advantageous in this scenario is that one is not constrained in one's search by "silos" or "preserves" (Degkwitz) in the form of scientific journals, nor is interdisciplinary research restricted through the too-narrowly defined topics of the various journals.

In a second step, we want to introduce an instrument for quality assurance for our platform, one that is oriented toward the principles of the peer review process, but expands it based on the contemporary possibilities of digital networks and communication: Scientists can evaluate any article on the platform positively (similarly to the " +1 " concept on Google+ or MathOverflow) or leave a comment. Additionally, it is possible to compose a complete reader's report containing the same elements as in a classical peer review, for example originality, novelty of the results, thoroughness, language, and form. These criteria can be evaluated individually and then summarized in an overall judgment. The reviewer also has to offer a (detailed) commentary on the work, like in a conventional referee report. Two factors are important here: neither the reviewer's response nor the commentary is anonymized; rather, both are identified with the full name of the writer, whose complete research profile is accessible (via ORCID). This is important in order to afford the highest possible level of transparency, which would not be ensured in the event that the identities of reviewers or commentators are withheld. Such a procedure is called Open Peer Review $(O P R)$ - should it take place after publication as described in our thought experiment, then it is called (Open) Post-Publication Peer Review (PPPR). PPPR is used by F1000, The Winnower, and ScienceOpen, for example, while $O P R$ is now supported by a range of newer platforms or Megajournals (PLoS Medicine, Peer]). The further new element is voluntariness: Reviewers can decide spontaneously and for themselves whether they want to compose a commentary or response. It stands to reason that such a readiness is more likely to exist for an article that a scientist has already read because of their own research interests, rather than for an article that has been 
externally assigned by a scientific journal for review - often also at an inconvenient point in time.

\section{WHAT ARE THE ADVANTAGES?}

A significant advantage of this open, transparent procedure lies, on the one hand, in the quality of the responses composed, which would surely be just as good, if not even greater, than in the classical anonymized review process. About half of the polled scientists came to this appraisal in a survey conducted by the STM Organization in 2008 [4]. The readiness to submit a sound response increases particularly when the review is citable, which could be realized through the allocation of a DOI for the review, as for the article itself. The author has the opportunity to answer the commentaries or reviews directly, which we otherwise only know from closed peer review procedures. In this way, the concept of the classical peer review is further developed to a proper discourse, in indispensable element of communication among researchers that has informed scholarship for centuries. As a result of the feedback that an author receives in this manner, it is possible to undertake corrections and revisions that serve to improve the original article. This process is thereby completely temporally decoupled from publication; it can take place a few weeks or years after the first publication, depending whether and to what degree the author deems an adjustment necessary. The new versions of the article receive a revised DOI that specifically identifies the relevant version of the article and thus further ensures the exact citation of all versions.

Here, we recognize a great advantage vis-à-vis classical scientific journals, wherein usually only two selected referees give reviews at a specific point in time, shortly after the submission of the manuscript, which of course later insights or the advice of further reviewers can no longer influence. The article then appears in the Internet or the printed volume of a journal "as though written in stone" - changes or corrections are only possible through "Comments" or as a "Note added in Proof," if at all - an outdated procedure from a time when print-based workflow allowed no other alternatives. That notwithstanding, it is remarkable that even today this process is maintained all the same by nearly all of the 20,000 STM scientific journals.

\section{ALTMETRIC INSTEAD OF IMPACT FACTOR}

The shortcomings of the Journal Impact Factor (JIF) have been faulted by many scientists and librarians. By 1997, studies already indicated that the JIF should not be used to evaluate research [5]. Even the "inventor" of the JIF, Eugene Garfield, declared in 1999 that the Impact Factor was not a perfect tool for measuring the quality of professional articles [6]. Nonetheless, many institutions still use the JIF in order to compare and evaluate researchers and research. This is a calamitous mistake, as one journal that profits strongly from the hype around the Impact Factor self-critically noted: In 2005, Nature determined that a small fraction of published works contributed disproportionately to the JIF; in the period under consideration, $89 \%$ of the JIF was produced by only one quarter of all publications [7]. The editorial by Nature moreover confirmed Eugene Garfield's determination regarding the misguided correlation between the quality of an article and the Impact Factor of the journal in which it is published [7]. Rather than the Impact Factor, the logging of citations per article is a far more meaningful measure, whereby this onedimensional number can of course only indicate the number of an article's mentions in newer publications. For this number contains no indications about, for example, whether it was a positive or negative citation and what precisely was cited: whether only a certain detail, such as an image or figure, or the summarizing conclusion. Additionally, the census of all mentions of an article on social networks is helpful, as is offered by the London start-up Altmetric and in the meantime is also used by a range of established publishers and scientific journals as Article Level Metrics. Besides the number of mentions on social networks like Twitter, Google+, or Mendeley, the article's reader also receives information about the author of a tweet or post, along with the post's content. This further information can serve to assess the quality of an article much more exactly, and above all closer to the time of publication than has previously been possible. Moreover, every institute or community could establish its own individual criteria, which by means of these Article Level Metrics would be transparent and open to scrutiny. This in turn would lead to a more fair evaluation of the scientific contribution of individual article to its field of research and finally thereby of the achievement of individual researchers or their institutions.

\section{COLLECTIONS INSTEAD OF JOURNALS?}

A last remaining point of criticism regarding our new platform could be that the individual compilation of articles by publishers - such on the occasion of this special issue of Laborjournal - would be cease to exist. That is true at first glance, but in our thought experiment we can also replace this trait of classical scientific journals through a procedure that is distinguished by a far greater level of flexibility: Classical scientific journals and their frequency of publication in volumes or issues are limited in terms of time and space according to the timing of their publication and the publisher that issues them. On our platform, we want to create an opportunity independent of those constrictions, on which one can create a collection any time and with any article. This flexible concept was introduced by $F 1000$ at the beginning of 2014 and has been practiced for a longer time by PLoS, but the selection of articles remains limited to those published on an organization's own platform. We lift this spatial restriction through being fundamentally able to integrate any article that appeared at whatever time or on whatever server or in any given source into a Collection [8]. Similarly to the process for publishers of scientific journals, this selection is made by one or more editors who represent a certain specialty. But differently to classical publishers, these editors would not work for the press that issues the journal, but rather 
independently and voluntarily. These collections can be added to or changed at any time, and the use of all articles will be recorded cumulatively in its entirety [9]. My collection on the admittedly quite specific topic "Perspectives of Scholarly Publishing," posted on the platform ScienceOpen in mid-April 2015 and which contains 42 scholarly articles meanwhile, was already accessed more than 9,000 times within four months. Articles can thus be included in different collections, which are the further deciding difference to scientific journals and represents a great advantage in the age of more and more interdisciplinary research. In this way, readers can use collections to gain a "filtered" overview of the most important works in their specialty, for example, whereby the selection is made subjectively by colleagues within the field. Here, collections take over the role of "filtering," which we thus far only were familiar with in the context of classical scientific journals.

\section{OPEN ACCESS - ALL OR NOTHING?}

We have not taken into account one obvious aspect in the discussion of our new platform thus far, possibly because in the meantime it has become an expectation that is nearly taken for granted, not just by research funders or politics but also many researchers: Open Access. The afore-described procedure only works if all results, data, and reviews are openly available and freely accessible. Hence, classical subscription-based business models by which scientific journals were commonly sold to libraries for decades reveal themselves to be incompatible with the purpose of a platform meant to enable the free and unimpeded discourse of scientists. Peter Suber summarized the significant aspects of Open Access and its advantages as early as 2002 [10]. If one follows the newest developments in Holland and currently also on the EU level, then surely it is less a question of "if" than of "when" this model will be implemented as a business model across the board in the scientific research landscape.

The vision of a new platform for scientific communication and documentation sketched out here is not new. As early as 2011, the British mathematician and Fields Medal winner Timothy Gowers offered similar thoughts on the expansion of arXiv to an open referee system, which were discussed on his blog very intensely by many researchers [11]. This observation alone reveals that the concept borrowed from blogs also works in the scientific realm and can represent a promising form of support for scientific discourse. The nexus of Open Access and $O P R$ was described and discussed in great detail by Nikolaus Kriegeskorte [12]. The by now intensive debate about the aspects described here shows that these ideas are no longer merely thought experiments or flights of fancy of some Open Access fanatics, but much more a reality coming ever closer. In the meantime, an array of newly founded publication platforms or Megajournals uses individual elements, for example OPR. Nevertheless, the number of articles posted on those platforms represents an almost vanishingly small figure compared to the approximately 1.8 million articles published in classical STM specialist journals in 2014. Moreover, in 2013 the number of articles published worldwide via Open Access was only about 130,000 , which even so was $32 \%$ more than the figure from the year before [13]. Should the attempt to publish all research articles - subject to the respective standards of the supporting organizations or institutions - via (Gold) Open Access be successful, a significant prerequisite for the implementation of the above-described process would be met. Nevertheless, this is not a necessary requirement for advancing 21st century scientific communication.

\section{A CLEAR CONCLUSION}

Classical scientific journals, at least in the natural sciences and medicine, have served their time. There is no longer a technical or procedural reason to publish new research findings exclusively in the form of scientific journals. New interdisciplinary platforms that expand upon existing repositories or institutional servers will, in the intermediate term, replace scientific journals, with few exceptions. For the first time, with these new platforms, the scientific discourse will be advanced by means of the possibilities of a networked community of researchers and the digital technologies of the 21st century. Today, every scientist is in control of whether he continues to choose journals in which he and his colleagues publish according to prestige and impact factor or wishes to take advantage of the far greater chances that present themselves through the manifold new possibilities of social networks and digital infrastructure today, which we already see in the use of the ScienceOpen platform, on which about 2 million Open Access articles and about 8 million referenced article records are currently available [14].

\section{ABOUT THE AUTHOR}

Alexander Grossmann is a Professor of Publishing Management at the HTWK University of Applied Sciences in Leipzig. Before he joined that position, he studied Physics at RWTH Aachen and graduated in Physical Sciences at Research Center Julich. After positions as a PostDoc and Associate Professor in Tuebingen and Munich, he has been working in publishing industry as publishing director and managing director at different international companies for 12 years. He also founded the Internet research and publishing network ScienceOpen along with Tibor Tscheke in 2013.

\section{REFERENCES}

[1] Brembs B. Digitale Steinzeit. Laborjournal. 2014;7(8):22-25.

[2] Degkwitz A. Wie Open Access die Forschung verändert: Weg mit den Wissenskonserven. Tagesspiegel [cited 2014 June 16]. Available from: http://www.tagesspiegel.de/wissen/wie-openaccess-die-forschung-veraendert-weg-mit-den-wissenskonserven/ 10058452.html

[3] Jahrhundert-Beweis. Einsiedler verschmäht Mathe-Medaille. SpiegelOnline [cited 2006 Aug 22]. Available from: http://www. spiegel.de/wissenschaft/mensch/jahrhundert-beweis-einsiedlerverschmaeht-mathe-medaille-a-432910.html

[4] Grossmann A. Where did our Peer Review Mojo go? ScienceOpen Blog [cited 2014 Sep 29]. Available from: http://blog.scienceopen. com/2014/09/peer-review-mojo/ 
[5] Seglen PO. Why the impact factor of journals should not be used for evaluating research. BMJ. 1997;314:497. doi:10.1136/ bmj.314.7079.497

[6] Garfield E. Journal impact factor: a brief review. CMAJ. 1999; 161(8):979-980.

[7] Editorial. Nature 2005;435(7045):1003-1004.

[8] Grossmann A. A welcome to authors, users, and readers who want to explore a new way to collect scholarly content. ScienceOpen Res. 2015. doi:10.14293/S2199-1006.1.SOR-EDU.EYYXOX.v1

[9] Grossmann A. Perspectives in scholarly publishing. ScienceOpen. 2015. doi:10.14293/S2199-1006.1.SOR-EDU.CLSSV9W.v1

[10] Suber P. Open access to the scientific journal literature. J Biol. 2002;1(1):3. doi:10.1186/1475-4924-1-3

[11] Gowers T. Gower's Weblog Blog [cited 2011 Oct 31]. Available from: https://gowers.wordpress.com/2011/10/31/how-mightwe-get-to-a-new-model-of-mathematical-publishing/

[12] Kriegeskorte N. Open evaluation: a vision for entirely transparent post-publication peer review and rating for science. Front Comput Neurosci. 2012;6(79):1-18. doi:10.3389/fncom. 2012.00079

[13] van de Stelt W. Vortrag. Berlin: Academic Publishing in Europe (APE-15). 2015.

[14] Available from: http://www.scienceopen.com.

\section{COMPETING INTERESTS}

The author declares no competing interests.

\section{PUBLISHING NOTES}

(C) 2015 A. Grossmann. This work has been published open access under Creative Commons Attribution License CC BY 4.0, which permits unrestricted use, distribution, and reproduction in any medium, provided the original work is properly cited. Conditions, terms of use and publishing policy can be found at www.scienceopen.com.

Please note that this article may not have been peer reviewed yet and is under continuous post-publication peer review. For the current reviewing status please click here or scan the QR code on the right.

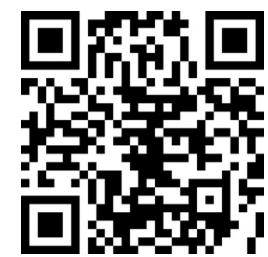

